\title{
Evolutionary patterns of Escherichia coli growth in seawater determined with a Host to Coast Environmental Laboratory Analog
}

\author{
Bradley S. Hughes* \\ Department of Ecology and Evolutionary Biology, and Department of Education, University of California, Irvine, \\ California 92697-2525, USA
}

\begin{abstract}
The present study investigated evolutionary patterns of Escherichia coli growth and survival in transmission through the coastal ecosystem between human host and seawater using a novel 'Host to Coast' Laboratory Analog simulating an $11 \mathrm{~d}$ sequence cycling through the $\mathrm{pH}$ and temperature conditions of the small intestine, colon, sewer, seawater, human stomach, and back into the small intestine. Although historically E. coli has been assumed to die off rapidly in seawater, a few instances of $E$. coli growth have been observed in environmental fresh water, soils, and nutrientenriched tropical seawater, suggesting the potential for evolving greater viability in such environments. This study investigated whether E. coli can evolve increased capacity for growth and survival in seawater through selective exposures to singular abiotic factors such as the high alkalinity or low temperatures approximating coastal aquatic conditions, and also whether adaptation to cycling $\mathrm{pH}$ can lead to increased growth fitness in a human host. Specialists and generalists were examined to reveal patterns of trade-offs in the multi-stress environment of the Analog. Dramatic increases in fitness revealed in the Host to Coast Ana$\log$ due to evolutionary exposure to alkalinity and cycling $\mathrm{pH}$ suggested that these factors are critically important in the evolutionary ecology of E. coli. Evolving the capacity for seawater survival and growth, combined with increased capability to infect human hosts, could facilitate $E$. coli infection from seawater exposure. Results suggest implications for wastewater management in order to prevent superior strains of pathogenic E. coli from evolving.
\end{abstract}

KEY WORDS: Experimental evolution - Escherichia coli . Evolving pathogens - Seawater, Water quality management · Human host · Microbial ecology · Multi-stress

Resale or republication not permitted without written consent of the publisher

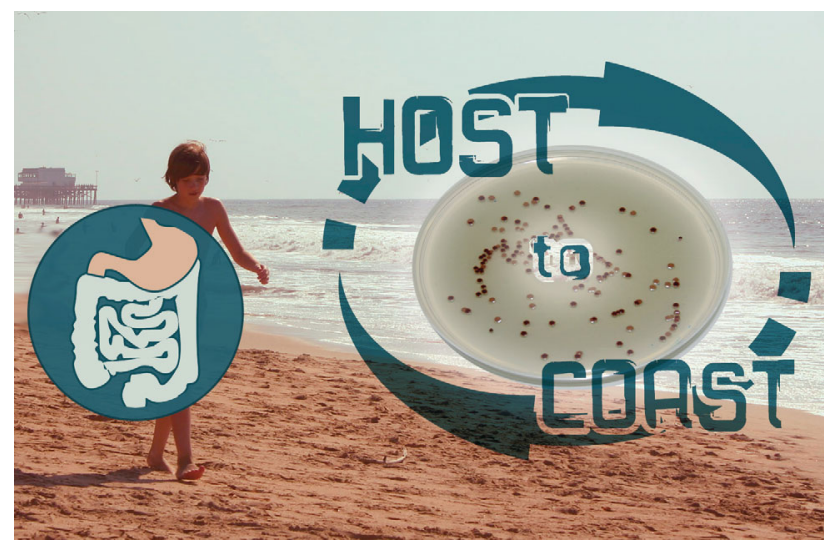

Host to Coast Environmental Laboratory Analog illustrated with images of coastline, host, and colonies of evolving Escherichia coli bacterium.

Illustration/Photo: Shane Hunter Hughes

\section{INTRODUCTION}

\section{Escherichia coli in the environment}

Over millions of years the enteric bacterium Escherichia coli has evolved to life inside human and other mammalian hosts in an environment characterized by warm temperatures and acidic or neutral $\mathrm{pH}$. Wide-scale attention to the serious dangers of pathogenic E. coli to health has focused largely on its transmission through cattle and has led to its gradual reduction in ground beef (Naugle et al. 2006). However, pathogenic $E$. coli is now finding its way into recreational waters (Dziuban et al. 2006), which may represent an important new trend in transmission. Rapid urban development in coastal regions has resulted in increased volumes of sewage discharge and urban 
runoff to the coastal ocean (Noble et al. 2003, Ahn et al. 2005), with various strains of $E$. coli being released to the marine bathing water. E. coli have long been assumed to die off rapidly in seawater and to lack the ability to grow and proliferate in the ocean (Savageau 1983), so their presence has been interpreted and used to indicate a recent introduction, i.e. sewage spill. However, studies have also shown that E. coli can grow in nutrient-enriched seawater (Jannasch 1968, Lopez-Torres et al. 1988), as might occur within highly eutrophic regions of a river mouth, in near-shore marine or lake sediments (Solo-Gabriele et al. 2000, Ishii et al. 2006), or possibly around sewage plumes. While beach closures have relied upon levels of E. coli detected as a mere indicator of dangers, there should be a growing concern, spurred by increasingly frequent outbreaks reported by the Centers for Disease Control and Prevention (CDC-USA) (Dziuban et al. 2006), about the potential spread of pathogenic strains of the E. coli itself through our coastal ecosystem. Those concerns prompted the present study. Could this organism evolve increased growth and survival in seawater through selective exposure to novel abiotic factors of high alkalinity or low temperatures found in the modern sewer or marine environment? In tropical freshwater environments, E. coli have been found in the absence of known fecal sources (Jimenez et al. 1989). Since a different strain was similarly tested and quickly died off, Jimenez et al. (1989) suggested the possibility that the natural isolate may have become genetically adapted to that environment. More recently, Ishii et al. (2006) reported evidence of naturalized autochthonous $E$. coli growing in temperate soil. The present study sought to establish a laboratory analog method to determine the correlated evolutionary role that various environmental factors can play in E. coli's potential evolution of increased fitness for the coastal environments of seawater and human host. Experimental lineages of this bacterium adapted to the environmental factors of temperature (Bennett et al. 1992) and $\mathrm{pH}$ (Hughes et al. 2007a,b) were previously derived and available for this purpose.

The successful colonization of bacteria must be adapted so that they survive transmission through the human gut's extreme fluctuating acidity, which ranges approximately between $\mathrm{pH} 2$ and 7 (Nugent et al. 2001). A swimmer, ingesting as few as 10 cells, may be infected by Escherichia coli with its highly evolved acid tolerance, while Salmonella, with an acid tolerance limited to a pH of only 3.0, requires over 10000 cells to produce a similar infection (Audia et al. 2001). This superior infective ability makes $E$. coli a potentially more dangerous environmental pathogen than Salmonella or other less acid-tolerant waterborne bacteria. Studies with non-pathogenic E. coli show that highly significant increases of fitness in respect to acid tolerance can happen in less than 1000 generations (Hughes et al. 2007a,b). Pathogenic and non-pathogenic strains of $E$. coli have similar resistance to acidity (Lin et al. 1996), so the experimental evolutionary study of non-pathogenic strains may be helpful in predicting the patterns one may observe in the natural evolution of pathogenic E. coli in the environment. During alkaline stress the peptidoglycan layer of Gram-negative bacteria, weakened by high $\mathrm{pH}$, may be less capable of protecting the cytoplasmic membrane of E. coli (Mendonca et al. 1994). Using the methods of experimental evolution, we recently discovered that long-term evolutionary exposure to alkaline $\mathrm{pH} 7.8$, near that of the ocean or sewers, can promote the evolution of bacterial lines with increased resistance and higher fitness toward alkalinity and also some surprising instances of correlated increased fitness in respect to acidity (Hughes et al. 2007a,b).

\section{Experimental evolution}

Experimental evolution is a particularly well-suited method for effectively examining bacterial adaptation to abiotic environments, since such environments are easy to regulate and control in a laboratory, and multiple replicate populations of bacteria can be exposed simultaneously to identical conditions. Evolutionary experiments are usually conducted through 3 possible approaches: artificial truncation selection, laboratory culling selection, or laboratory natural selection (Rose et al. 1990). To maximize the realism of the evolutionary patterns evolved, this study specifically utilized laboratory natural selection, exposing the microbe to a novel environment in which intra-population competition alone determines which traits are favored (Bennett 2003). Whatever traits naturally play a role will be selected through competition within the given environment in much the same way evolutionary selection might occur naturally, but eliminating the complication of interspecies competition.

Many experimental evolution studies have investigated beneficial adaptation directly within the experimental selection environments, and results of direct fitness gains have been well demonstrated with microbial populations. However, the present study utilizes a more unusual approach of measuring correlated fitness, also referred to as preadaptation or exaptation, within novel environmental conditions. Such an approach is especially advantageous for this investigation, since the multi-stress environment of seawater does not permit the growth of $E$. coli necessary for evolution in that aquatic environment to occur directly. This limitation was navigated here by evolving the 
bacteria under less complicated and more tractable environmental stresses, in which evolutionary propagation could proceed. The lineages of genotypes evolved by these various environmental forces could then be measured for fitness in the more complex seawater conditions, implicating specific environmental forces for their potential to cause correlated adaptation to the novel environments of the coastal ecosystem. Fortunately, in addition to further characterizing more complex evolutionary patterns for extending the study of evolution itself, this method would also be informative for investigating important environmental questions, such as whether long-term exposure to alkaline sewage systems might evolve pathogenic E. coli that could survive and proliferate in seawater. As the field of experimental evolution progresses, such correlated studies may prove increasingly important as researchers search responsibly for previously unforeseen evolutionary effects.

Experimentally derived bacterial lineages adapted for 2000 generations to acid, alkaline, and cycling $\mathrm{pH}$ were used in this experiment, along with similarly derived lineages adapted to low and high temperature (Table 1). Derivation of each group involves daily transfer batch-culturing propagating 6.67 cell divisions within the defined $\mathrm{pH}$ or thermal conditions, i.e. constant $\mathrm{pH} 5.3$ (at $37^{\circ} \mathrm{C}$ ) for acid media (see Hughes et al. 2007a,b), precisely limiting glucose to control the number of the generations (Lenski et al. 1991). To calibrate and expand the Analog system to reflect the natural world, environmental Escherichia coli isolates (Table 1) taken from an urban sewer and coastal seawater were also included. This study bridges the disciplines of experimental evolution and aquatic microbial ecology, extending experimental evolutionary methods into multi-stress complexities more closely approximating the real world, while at the same time contributing a useful aquatic microbiological method for empirically estimating natural evolutionary patterns with laboratory control.

\section{Purpose of the Host to Coast Analog}

A laboratory experiment was developed to provide a controlled test of the relative importance of different evolutionary factors evolving increased growth and survival of Escherichia coli within the coastal ecosystem. The present experiment was not intended to evolve bacteria within the Host to Coast Analog itself, but rather, was designed to test the hypothesis that prior adaptation to alkaline, acid, cycling environmental $\mathrm{pH}$, or high or low temperature would lead to increased survival, growth, and fitness in seawater and a human host. This Host to Coast Analog involved a much more realistically complex, sequential combination of multi-stress environments than had ever previously been used to measure evolutionary patterns. Specifically, the laboratory analog simulated an $11 \mathrm{~d}$ sequence cycling through the $\mathrm{pH}$ and temperature conditions of the small intestine, colon, sewer, seawater, human stomach, and back into the small intestine; development of this (henceforth termed 'Host to Coast Environmental Laboratory Analog'; Table 2) was designed for a balance of tractability and realism, through iteratively approximating parameters of $\mathrm{pH}$, temperature, and media to natural environmental levels, as closely as could be afforded within the constraints of utilizing the media and methods typically employed for microbial evolutionary experimentation with E. coli (see Lenski et al. 1991, Bennett et al. 1992, and Hughes et al. 2007a,b). For experimental control, other abiotic factors such as light radiation (Fujioka et al. 1981) or biotic factors such as protozoan grazing (Barcina et al. 1992) were excluded from the scope of this analog design. Although models can always be improved, to our knowledge, the Host to Coast Analog described here represented the first successful attempt to link natural-selection-based experimental evolution to the microbial ecological pattern of transmission through the coastal ecosystem between human host and seawater, with repeatable controlled laboratorybased methods.

\section{Host Analog design}

Although it may be experimentally challenging, it is possible to estimate pathogen behavior under controlled conditions that approximate gastric conditions (Tamplin 2005). An earlier attempt by other researchers to model bacteria survival in a stomach, with a $\mathrm{pH}$ decrease immediately below 2.0, could find no

Table 1. Escherichia coli. Experimental bacterial lines. Terminology of study: terminology used in this article to refer to each E. coli Line; Reference name: official archival name for reference to stored E. coli Lines; Source: first published article to refer to each E. coli Line. -: not previously published

\begin{tabular}{|c|c|c|}
\hline $\begin{array}{l}\text { Terminology } \\
\text { of study }\end{array}$ & $\begin{array}{l}\text { Reference } \\
\text { name }\end{array}$ & Source \\
\hline Acid & AFB739 5+1 & Hughes et al. (2007a) \\
\hline Alkaline & AFB757 8+1 & Hughes et al. (2007a) \\
\hline Cycled pH & AFB763 E+1 & Hughes et al. (2007b) \\
\hline $14^{\circ} \mathrm{C}$ & AFB1170 14A/+ & J. Schlumbohm (unpubl.) \\
\hline $42^{\circ} \mathrm{C}$ & REL2142 42+1 & Bennett et al. (1992) \\
\hline Host Isolate & AFB1258 S10 & - \\
\hline Coast Isolate & AFB1260 E13 & - \\
\hline Ancestor/Control & 1 REL1206 A- & Lenski et al. (1991) \\
\hline
\end{tabular}


Table 2. Host to Coast Environmental Laboratory Analog. Experimental conditions of temperature, $\mathrm{pH}$, and culture medium, as sequenced in the Analog. Seawater (see Table 3 for characterization) was sampled from Balboa Pier in March 2006 and filtered; Acid Cycle (see Fig. 1 and 'Host Analog design' section for details) involves gradual acidification in the stomach and gradual neutralization near the pancreatic duct in the duodenum. LB: Luria-Bertani broth; DM: Davis Minimal Media

\begin{tabular}{|c|c|c|c|c|}
\hline $\begin{array}{l}\text { Day of } \\
\text { Analog }\end{array}$ & $\begin{array}{l}\text { Environment } \\
\text { simulated }\end{array}$ & $\begin{array}{c}\text { Temperature } \\
\left({ }^{\circ} \mathrm{C}\right)\end{array}$ & $\mathrm{pH}$ & $\begin{array}{l}\text { Culture } \\
\text { medium }\end{array}$ \\
\hline $\begin{array}{l}\text { Day } 1 \\
\text { (Host) }\end{array}$ & $\begin{array}{l}\text { Proximal } \rightarrow \text { distal } \\
\text { small intestine }\end{array}$ & 37 & $6.8 \rightarrow 7.7$ & LB \\
\hline $\begin{array}{l}\text { Day } 2 \\
\text { (Host) }\end{array}$ & $\begin{array}{l}\text { Right colon } \\
\text { Left colon }\end{array}$ & 37 & 7.0 & $\mathrm{DM}$ \\
\hline $\begin{array}{l}\text { Days } 3 \text { and } 4 \\
\left(\text { Coast }_{\text {Transition }}\right)\end{array}$ & $\begin{array}{l}\text { Sewer } \\
\text { system }\end{array}$ & 20 & $6.8 \rightarrow 8.2$ & LB \\
\hline $\begin{array}{l}\text { Days } 5^{\text {a }} \text { to } 9 \\
\text { (Coast) }\end{array}$ & Seawater & 14 & 8.2 & Seawater \\
\hline $\begin{array}{l}\text { Day } 10^{b} \\
\text { (Host) }\end{array}$ & $\begin{array}{c}\text { Stomach } \\
\text { acidification } \rightarrow \\
\text { intestine } \\
\text { neutralization }\end{array}$ & 37 & $\begin{array}{c}\text { Acid Cycle } \\
6.8 \rightarrow 2.0 \\
2.0 \rightarrow 6.8\end{array}$ & $\begin{array}{c}\mathrm{LB} \\
+\mathrm{HCL} \\
+\mathrm{NaHCO}_{3}\end{array}$ \\
\hline $\begin{array}{l}\text { Day 11' } \\
\text { (Host) }\end{array}$ & $\begin{array}{l}\text { Proximal } \rightarrow \text { distal } \\
\text { small intestine }\end{array}$ & 37 & $6.8 \rightarrow 7.7$ & LB \\
\hline
\end{tabular}

et al. 1998), and often involve the general anti-stress response encoded by the rpoS gene (Loewen \& HenggeAronis 1994). For example, under natural circumstances it is rare that exponential phase bacteria are released directly into seawater, but instead they are typically in stationary phase in their transit through wastewater (Gauthier et al. 1993), which was emulated in the Host to Coast Analog by bringing the E. coli to stationary phase by nutrient starvation before the sewer simulation and again during the sewer simulation prior to transfer to seawater. E. coli are least sensitive to the hyperosmotic shock of seawater when they are in stationary phase (Troussellier et al. 1998), so the realism of survival increases from stationary phase within environmental sewage or seawater was present in the Analog. Other design challenges were addressed, such as biofilm formations culturable cells (Beumer et al. 1992). Our choice of an initial stomach $\mathrm{pH}$ of 6.7 for the Analog Acid Cycle (see Fig. 1), which is typical immediately after meal intake rather than at fasting when $\mathrm{pH}$ is below 2.0 (Dressman et al. 1990, Russell et al. 1993), was made to avoid such a total loss of culturable bacteria and it is also a more realistic $\mathrm{pH}$ model condition for bacteria that are ingested with food. A $2 \mathrm{~h}$ acid cycle exposure time used in the Analog was modeled after stomach acid physiologies of young healthy adults, who require an average time of $127 \pm 13 \mathrm{~min}$ (mean $\pm \mathrm{SE}$ ) for $50 \%$ of their stomach contents to empty (Clarkston et al. 1997). Gradual acidification and alkalization with shaking, combined with additional time for repopulation growth during the small intestine simulation, were used to achieve a similarity to human physiology and to yield successful measurements of fitness, which would otherwise have been impossible.

\section{Coast Analog design}

The Coast Analog includes both transitional sewer

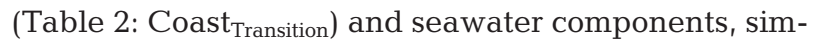
ulating the transmission of Escherichia coli from human host through a sewer into the coastal seawater prior to re-entry back into the host environment. It was modeled to include some aspects of bacterial preshock which typically occur in the multiple stresses of environmental microbial transmission (see Troussellier

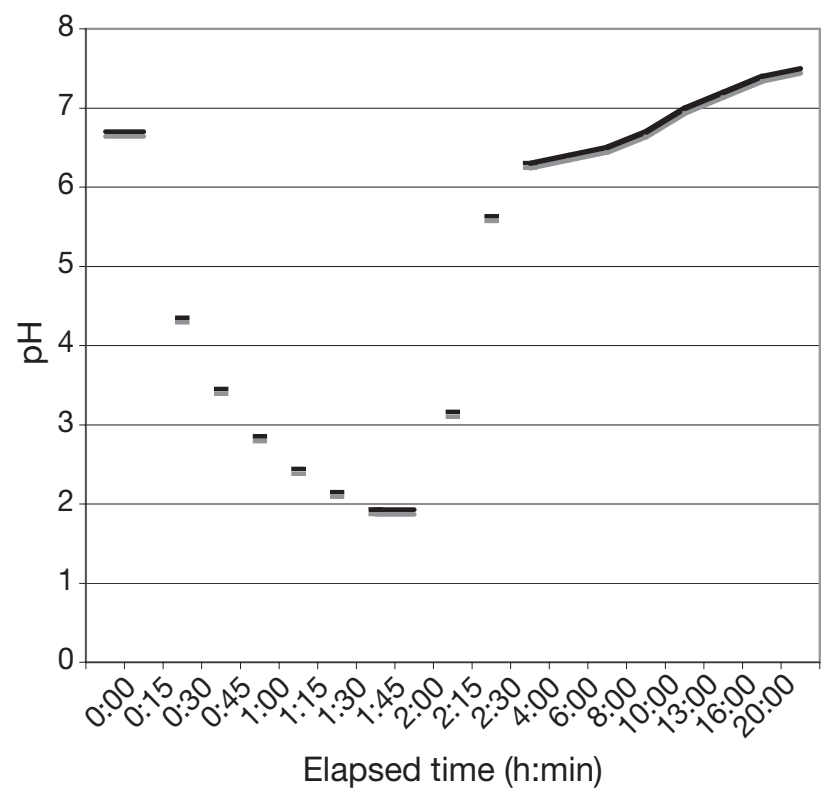

Fig. 1. pH of media versus time elapsed during the acid cycle of the Host Analog. Short discontinuous horizontal bars indicate rapidly shifted $\mathrm{pH}$ levels accompanying $0.9 \mathrm{ml}$ additions of $0.15 \mathrm{M} \mathrm{HCl}$ acid at times $0: 15,0: 30,0: 45,1: 00,1: 15$, and $1: 30 \mathrm{~h}$ during acidification and $0.5 \mathrm{ml}$ additions of $7.5 \%$ Solution $\mathrm{NaHCO}_{3}$ base at times 2:00, 2:15, and 2:30 h during neutralization. Continuous lines indicate sustained $\mathrm{pH}$ levels of flasks, beginning with a mixture of $9.6 \mathrm{ml}$ of Luria-Bertani broth (LB) media and $0.4 \mathrm{ml}$ seawater containing the competing bacteria, at time $=0: 00 \mathrm{~h}, \mathrm{pH}=6.7$; time $=1: 30 \mathrm{~h}, \mathrm{pH}=$ 1.93 ; and time $=2: 30 \mathrm{~h}, \mathrm{pH}=6.3$, then gradually increasing to 7.5 at elapsed time $=20: 00 \mathrm{~h}$ 
that were found in sewer conditions at lower temperatures $\left(\leq 14^{\circ} \mathrm{C}\right)$ and prevented accurate census. This problem was avoided by using a temperature of $20^{\circ} \mathrm{C}$, which simulated a warmer region sewer component. Another design issue was the transition from the sewer to the costal seawater, which required $0.8 \mathrm{ml}$ of the sewer Luria-Bertani broth (LB) to ensure countable numbers and to provide nutrients depleted by seawater filtration. This nutrient addition, which simulated the environmental factor of sewer leakage, also promotes E. coli growth in seawater (Jannasch 1968, Lopez-Torres et al. 1988). Therefore, the amount was precisely gauged to avoid growth in the Ancestor/Control population (see Fig. 2) while still allowing realistic persistence of populations in the Coastal Isolate Line.

\section{MATERIALS AND METHODS}

Culture techniques. All experimental groups were run with 6-fold independent replication. The culture media included unbuffered Luria-Bertani broth (LB); $\mathrm{LB}$ with added $150 \mathrm{mmol} \mathrm{HCl}$ and $7.5 \% \mathrm{NaHCO}_{3}$; buffered $\mathrm{pH}$ 7.0 Davis minimal media (DM); and filtered seawater (see 'Seawater collection, processing, and characterization' below) (Fig. 1), at controlled temperature and $\mathrm{pH}$, as described in Lenski et al. (1991) and Hughes et al. $(2007 \mathrm{a}, \mathrm{b})$, respectively. Cultures were propagated within $50 \mathrm{ml}$ Erlenmeyer flasks in $120 \mathrm{rpm}$ shaking incubators (New Brunswick Models G25 and G25-KC). To avoid discrepancies between viability and culturability of potentially viable-butnon-culturable cells (see Rozen \& Belkin 2001), all population enumerations were based on culturable cells counted on solid agar plates. Population counts of the 2 competitors were differentially enumerated through colony growth on tetrazolium-arabinose (TA) plates (in which a 21 batch contains $2 \mathrm{ml}$ of $5 \%$ triphenyltetrazolium-chloride, $20 \mathrm{~g}$ arabinose, $20 \mathrm{~g}$ tryptone, $2 \mathrm{~g}$ yeast extract, $10 \mathrm{~g}$ sodium chloride, and $32 \mathrm{~g}$ agar in 21 distilled water), on which the neutral marker for arabinose-utilizing Ara+ evolved strains displays white colonies that can easily be distinguished by their differing coloration compared to the Ara- ancestral strain that grows red colonies (see Lenski et al. 1991).

Origin of laboratory-derived lines of Escherichia coli. Evolved lines of E. coli examined in this study (Table 1) were founded from a common ancestor that was already well adapted to general laboratory conditions after 2000 generations of lab propagation (Lenski et al. 1991). $\mathrm{pH}$ evolution lines (constant temperature $37^{\circ} \mathrm{C}$ ) included an acid line evolved for 2000 generations at a constant $\mathrm{pH}$ of 5.3 and an alkaline line evolved for 2000 generations at a constant $\mathrm{pH}$ of 7.8 (see Hughes et al. 2007a), as well as a cycled pH line evolved for 2000 generations of continually alternating $\mathrm{pH}$ (from 5.3 to 7.8 on the first day and then from 7.8 to 5.3 on the subsequent day; see Hughes et al. 2007b). The 2 thermal evolution lines (constant $\mathrm{pH}$ 7.0) included a lineage evolved for 2000 generations at a constant temperature of $14^{\circ} \mathrm{C}$ and another at $42^{\circ} \mathrm{C}$ (Bennett et al. 1992).

Origin of natural isolate lines of Escherichia coli. By including comparative analysis of natural isolates versus the control bacterium that is also the experimental ancestor, we sought to better characterize the effective calibration of this system for real world relevancy. Two natural isolates of $E$. coli were obtained from human waste and from seawater samples, to represent 'Host' and 'Coast', respectively. The natural Host isolate was obtained from the primary sewage effluent from the Irvine Ranch Water District, California, USA, on February 13, 2006, and the natural Coast isolate was obtained from surface seawater collection off the end of Balboa Pier, Newport Beach, California, USA, on January 21, 2005. These natural Host and Coast strains were isolated on mTEC agar (Difco) and confirmed to be excellent matches to E. coli by API 20-E biochemical substrate tests (bioMerieux). These natural isolates were positive (+) for the arabinose marker, enabling their quantification by identical methods to that of the experimental evolution lines.

Seawater collection, processing, and characterization. Seawater was collected by 15-gallon carboy from the coastal Pacific Ocean near Balboa Pier. The homogeneously mixed water sample was filtered through tangential flow filtration (Pall Filtron LV Centramate TFF System) with a $0.22 \mu \mathrm{m}$ pore sized cartridge to remove bacteria and other large plankton. Filtrates were stored at $-20^{\circ} \mathrm{C}$ and thawed for $2 \mathrm{~d}$ at $5^{\circ} \mathrm{C}$ with shaking for $20 \mathrm{~min}$ prior to use. Analysis of seawater characteristics was conducted via high temperature combustion using the Shimadzu TOC-V in the shorebased laboratory at the University of California, Santa Barbara (Table 3) (see methods of Carlson et al. 2004). Other seawater characterizations were conducted at the University of California, Irvine (Table 3). Sea surface temperature was measured on site at Balboa Pier using an infrared gun (Raynger-ST, Raytek). Sample splits were analyzed for chlorophyll fluorescence (YSI 6025, YSI Incorporated) and conductivity (Model 162A, Thermo Orion); conductivity was subsequently converted to salinity using the practical salinity scale. Aliquots $(1.0 \mathrm{ml})$ of each sample were analyzed for fecal indicating bacteria (FIB) by 1:10 dilution into Butterfield's phosphate buffer solution (Hardy Diagnostics), followed by analysis using Colilert-18 (for total coliform and Escherichia coli) and Enterolert (for enterococci bacteria) tests (IDEXX), using 96-well quantitrays (Edberg et al. 1988). These tests yield the 
concentration of FIB in units of most probable number (MPN) of bacteria per $100 \mathrm{ml}$ of sample. Measurement of both filtered and unfiltered seawater is shown for comparison (Table 3), with the dissolved organic carbon (DOC) of the filtered seawater $35 \%$ less, dissolved organic nitrates (DON) lowered by $40 \%$, and phosphate reduced by $46 \%$ from that of the unfiltered levels. Salinity was not measurably affected by filtration, while the $\mathrm{pH}$ dropped from 8.27 to 8.16 during filtration.

Measurements of fitness. Relative survival and growth fitness of various $\mathrm{pH}$ and thermal evolutionary lines were measured through direct competition with the common Ancestor/Control, which serves as either an ancestor (more specifically an Ara- clone of the Ara+ ancestor), as a control or both. In the case of the laboratory-evolved lines, these measurements characterized evolutionary fitness changes in addition to serving as a control baseline for comparison. For natural Host and Coast Isolates, it served purely as a control baseline for transitive comparison to the evolved

Table 3. Seawater analyses for characterization of source and filtered seawater used in the Analog. Source seawater was gathered from surface water near the end of Balboa Pier on March 21, 2006, and its characteristics measured by single sample analysis. Filtered seawater was processed from the source seawater by filtering through a $0.22 \mu \mathrm{m}$ tangential flow system. It was then frozen, thawed, and used for the Coast Analog. Mean $\pm 95 \%$ confidence interval (CI) is based on a sample size of 5 for each characteristic analyzed and a significance level of $\alpha=0.05$. UCSB and UCI: analyses performed at University of California, Santa Barbara and University of California, Irvine, respectively (see 'Materials and methods: Seawater collection, processing, and characterization'). DOC: dissolved organic carbon; TN: total nitrogen; DON: dissolved organic nitrogen; FIB: fecal indicating bacteria; TC: total coliform; EC: Escherichia coli; ENT: enterococci; MPN: most probable number; -: eliminated by filtration

\begin{tabular}{|lcc|}
\hline Characteristic & $\begin{array}{c}\text { Source } \\
\text { seawater }\end{array}$ & $\begin{array}{c}\text { Filtered } \\
\text { seawater } \\
\text { (mean } \pm 95 \% \mathrm{CI})\end{array}$ \\
\hline UCSB & & \\
DOC $(\mu \mathrm{M})$ & 170.207 & $110.689 \pm 5.994$ \\
TN $(\mu \mathrm{M})$ & 17.960 & $10.810 \pm 1.325$ \\
DON $(\mu \mathrm{M})$ & 14.091 & $7.301 \pm 1.202$ \\
Phosphate $(\mu \mathrm{M})$ & 0.689 & $0.371 \pm 0.024$ \\
Nitrite $(\mu \mathrm{M})$ & 0.222 & $0.068 \pm 0.016$ \\
Nitrite + Nitrate $(\mu \mathrm{M})$ & 2.862 & $2.798 \pm 0.037$ \\
Ammonia $(\mu \mathrm{M})$ & 1.006 & $0.712 \pm 0.126$ \\
UCI & & \\
pH & 8.270 & $8.162 \pm 0.007$ \\
Salinity $($ ppt) & 32.700 & $32.700 \pm 0.048$ \\
Chlorophyll $\left(\mu g \mathrm{l}^{-1}\right)$ & 30.000 & - \\
FIB:TC (MPN per $100 \mathrm{ml})$ & 216.000 & - \\
FIB:EC (MPN per $100 \mathrm{ml})$ & 30.000 & - \\
FIB:ENT (MPN per $100 \mathrm{ml})$ & 10.000 & - \\
& & \\
\hline
\end{tabular}

lines. The relative fitness of an experimentally evolved line was calculated from the ratio of the logarithm of population growth doublings achieved by the experimental competitor compared to that of the Ancestor/Control (Lenski et al. 1991). A relative fitness significantly greater than 1.0 signifies improved evolutionary fitness or superiority to the ancestor, while a relative fitness significantly less than 1.0 denotes an evolved loss in fitness compared to the ancestor (Lenski et al. 1991). Since Escherichia coli does not typically divide and grow in seawater, the relative fitness measurement for this phase of the Analog was necessarily modified to detect mere persistence, substituting linear ratios of survival in place of the logarithmic doubling function, and is referred to as relative survival fitness. Quantitative interpretations remained otherwise synonymous, with superiority of the experimental line over the ancestor evident when relative survival fitness measured greater than 1.0 and vice versa. Counting the mixed competitors via plating was facilitated by a distinguishable marker of the colony color when grown on TA plates, which was facilitated by the differential $(-$ or + ) capacity for arabinose utilization present between the Ancestor/Control and all of the experimental lines. This arabinose marker has been shown to be neutral for fitness effects in many environments, including temperature and $\mathrm{pH}$ (Bennett et al. 1992, Hughes et al. 2007a). These platings of competitive census were conducted on all possible tractable and relevant days, which were limited exclusively yet effectively to only those points before and after Coast Analog and before and after the Host Analog.

Analog sequence Day 1 (Host). Day 1 of the Analog sequence approximated the $37^{\circ} \mathrm{C}$ temperature of a human host along with a $\mathrm{pH}$ in the proximal small intestine of 6.8 , climbing gradually to 7.7 at the distal end (Sasaki et al. 1997). This variation in $\mathrm{pH}$ was efficiently achieved by simply inoculating the bacteria into unbuffered LB medium and allowing it to gradually rise in $\mathrm{pH}$ from metabolites of cellular growth produced during the day in the $37^{\circ} \mathrm{C}$ shaking incubator (verified with Fisher Accumet Model $15 \mathrm{pH}$ meter).

Analog sequence Day 2 (Host). Day 2 of the Analog placed the Escherichia coli in the colon, with a temperature of $37^{\circ} \mathrm{C}$ and $\mathrm{pH}$ of 7.0 (as averaged between the right and left colon measurements of $\mathrm{pH} 6.8$ and 7.2 made by Sasaki et al. 1997). A total of $0.1 \mathrm{ml}$ was transferred from Day 1 flasks into $9.9 \mathrm{ml}$ of buffered $\mathrm{pH} 7.0$ $\mathrm{DM}$, incubated at $37^{\circ} \mathrm{C}$. DM was substituted for LB to simulate the poor nutrient condition within the colon.

Analog sequence Days 3 and 4 (Coast). Days 3 and 4 of the Analog simulated a sewer, with a temperature of $20^{\circ} \mathrm{C}$ and $\mathrm{pH}$ increasing gradually from 6.8 to 8.2 , as may be typical for sewer systems attempting to match their outlet $\mathrm{pH}$. A total of $0.1 \mathrm{ml}$ was transferred from 
Day 2 flasks into $9.9 \mathrm{ml}$ of unbuffered LB and then the alkalinity was allowed to rise from accumulation of metabolites during $2 \mathrm{~d}$ of prolonged incubation.

Analog sequence Days 5 to 9 (Coast). Days 5 through 9 of the Analog represented 5 days submerged in coastal seawater during the month of March, when Southern California coastal seawater temperatures averaged near $14^{\circ} \mathrm{C}$ and $\mathrm{pH}$ was near 8.2 (Table 3) in the source seawater obtained in midMarch of 2006 for this experiment. Such rainy-season months correlate with high wastewater spillage. Five days in seawater at $14^{\circ} \mathrm{C}$ causes Escherichia coli to exhibit a dramatically higher death rate compared to lower temperatures (Vasconcelos \& Swartz 1976), so this temperature was optimal for detecting differential survival of the bacterial lines.

Transition into the seawater initiated the beginning of the relative survival fitness competition between the common Ancestor/Control line and each experimental line (Plating 1). These measurements commenced by transferring $0.4 \mathrm{ml}$ from the Ancestor/Control line culture and $0.4 \mathrm{ml}$ of an experimental line at the end of Day 4, for a total of $0.8 \mathrm{ml}$, into $9.2 \mathrm{ml}$ of the seawater media, in which it was incubated for $5 \mathrm{~d}$. Then, $0.4 \mathrm{ml}$ from the seawater flasks was transferred into $9.6 \mathrm{ml}$ of LB and final seawater survival counts were obtained by a second TA plating (Plating 2).

Analog sequence Day 10 Acid Cycle (Host). Day 10 of the Analog represented transmission from $14^{\circ} \mathrm{C}$ seawater into a human host at $37^{\circ} \mathrm{C}$, through the acidity cycle of the stomach's secretion of $\mathrm{HCl}$ and passage into neutralization in the small intestine through $\mathrm{NaHCO}_{3}$ secretion at the duodenum (Montrose 2001). Final seawater survival counts also served as the initial counts for the growth competition in the Host component of the Analog (Plating 2). Acidification and alkalization sequence (see Fig. 1) was carried out gradually through 6 stepwise $0.9 \mathrm{ml}$ additions of $150 \mathrm{mmol} \mathrm{HCl}$, the human physiological concentration of cephalic phase parietal cell secretion (Guyton \& Hall 2000), administered directly into fresh bacteria-containing LB flasks (120 rpm shaking) at 15 min intervals to reduce pH from 6.7 down to slightly below 2.0 over the course of $1.5 \mathrm{~h}$. The flasks remained at this low $\mathrm{pH}$ for $30 \mathrm{~min}$ before commencing neutralization by 3 stepwise $0.5 \mathrm{ml}$ additions of $7.5 \% \mathrm{NaHCO}_{3}$ administered at $15 \mathrm{~min}$ intervals to increase $\mathrm{pH}$ from below 2.0 to 6.3 over the course of a further $45 \mathrm{~min}$. During the extreme acidity phase of this cycle, culturable bacterial counts decreased to levels undetectable by plating, so the remaining bacteria were allowed to repopulate competitively through the remainder of the $20 \mathrm{~h}$ acid cycle of the Host Analog (Table 3), as the unbuffered LB media continued to rise gradually from $\mathrm{pH} 6.3$ to 7.5 through build up of alkalizing cellular metabolites.
Analog sequence Day 11 (Host). The rising $\mathrm{pH}$ of Day 11 was analogous to the physiology of a gradual transport between the proximal and distal end of the small intestine ( $\mathrm{pH} 6.5$ to 7.5) (Nugent et al. 2001). After this competitive repopulation day, a third TA plating served as the final measurement of bacterial growth in the host. This marked the end of the completed sequence of the Host to Coast Analog (Plating 3).

Statistics. Mean fitness values of all lines were based on 6 replicates for each assay. Significance of evolved relative fitness means were analyzed by $t$-distributions compared to a null hypothesis value of 1 , representing fitness equal to the Ancestor/Control. Conservative 2-tailed probabilities were employed consistently, with the number of independent replications used to establish the degrees of freedom, which were $\mathrm{df}=\mathrm{n}-1=5$ in every case, except for seawater analysis which used $\mathrm{df}=\mathrm{n}-1=4$. In all tests, $\alpha=0.05$ was used to delineate significance. The test for similarity between mean fitness of different lines evolved in the same evolutionary conditions was analyzed using the Tukey-Kramer test for comparison of means. The fitness measurements produced in the various conditions of the Host to Coast Analog tested only a priori hypotheses.

\section{RESULTS}

\section{Growth fitness in the Host}

Fitness in the Host component of the Analog was measured for each of the experimental lines through direct competitions with the common Ancestor/Control bacterium (Table 4). These measurements pro-

Table 4. Host Analog relative growth fitness (mean $\pm \mathrm{SE}$, based on 6 replicate tests for each evolved or natural isolate experimental line) of experimental lines tested in competition with the ancestral control bacterium in the laboratory environment of the Host Analog on Days 10 and 11. Twotailed probabilities were calculated using the $t$-distribution with $\mathrm{df}=\mathrm{n}-1=5$; the null hypothesis was that the mean fitness equaled 1

\begin{tabular}{|lcr|}
\hline $\begin{array}{l}\text { Experimental } \\
\text { E. coli Line }\end{array}$ & $\begin{array}{c}\text { Relative } \\
\text { growth fitness }\end{array}$ & $\begin{array}{r}\text { 2-tailed } \\
\text { probability }\end{array}$ \\
\hline Acid & $0.382 \pm 0.076$ & $<0.001$ \\
Alkaline & $0.997 \pm 0.028$ & 0.920 \\
Cycled pH & $1.186 \pm 0.019$ & $<0.001$ \\
$14^{\circ} \mathrm{C}$ & $1.154 \pm 0.036$ & 0.008 \\
$42^{\circ} \mathrm{C}$ & $0.556 \pm 0.014$ & $<0.001$ \\
Host Isolate & $2.117 \pm 0.096$ & $<0.001$ \\
Coast Isolate & $1.712 \pm 0.051$ & $<0.001$ \\
\hline
\end{tabular}


vided a transitive comparison between each of the experimental lines for their relative performance in environments simulating some of the stresses experienced in a human gastrointestinal tract. Population counts for each competitor and the common Ancestor/Control were enumerated once before the Host Analog acidification in the simulation of the stomach on Day 10 and again after the neutralization on Day 11 of the simulated day of passage through the small intestine. Interpretation of the measurements shown in Table 4 pivot around a relative growth fitness value of 1.0, with values significantly higher than 1.0 indicating increased fitness and values lower than 1.0 indicating a loss of fitness, relative to the Ancestor/ Control. The Acid Line (Table 4), with a long-term evolutionary exposure to the factor of constant acidity, had a fitness loss of $62 \%$, with a fitness of only 0.382 , in the Host Analog environment. Such a loss in fitness was not the case with the Alkaline Line, which had no significant change in fitness. The Cycled $\mathrm{pH}$ Line evolved a fitness gain of $19 \%(1.186)$ in the Host Ana$\log$ and the $14^{\circ} \mathrm{C}$ Line gained $15 \%$ (1.154) fitness, while the $42^{\circ} \mathrm{C}$ Line actually lost $44 \%$ (0.556) fitness. The natural Host Isolate Line had the highest fitness in this environment, with $112 \%$ better fitness compared to the Ancestor/Control. The natural Coast Isolate Line also had a very high fitness, at $71 \%$ higher level than the Ancestor/Control. Although these natural isolate line fitness performances are not relative to their ancestor, and therefore do not measure their actual evolution, they do provide a useful comparison to all of the other lines by transitive comparison to the Ancestor/Control, which functions here as a common control among all lines measured and thus allows characterization of both experimental and natural strains to be considered.

Table 5. Coast Analog relative survival fitness (mean $\pm \mathrm{SE}$, based on 6 replicate tests for each evolved or natural isolate experimental line) of experimental lines tested in competition with the ancestral control bacterium in the laboratory environment of the Coast Analog. Two-tailed probabilities were calculated using the t-distribution with $\mathrm{df}=\mathrm{n}-1=5$; the null hypothesis was that the mean fitness equaled 1

\begin{tabular}{|lcc|}
\hline $\begin{array}{l}\text { Experimental } \\
\text { E. coli Line }\end{array}$ & $\begin{array}{c}\text { Relative } \\
\text { survival fitness }\end{array}$ & $\begin{array}{c}\text { 2-tailed } \\
\text { probability }\end{array}$ \\
\hline Acid & $1.144 \pm 0.279$ & 0.263 \\
Alkaline & $2.909 \pm 0.469$ & 0.010 \\
Cycled pH & $0.996 \pm 0.020$ & 0.866 \\
$14^{\circ} \mathrm{C}$ & $1.050 \pm 0.083$ & 0.570 \\
$42^{\circ} \mathrm{C}$ & $1.124 \pm 0.030$ & 0.010 \\
Host Isolate & $0.213 \pm 0.013$ & $<0.001$ \\
Coast Isolate & $1.457 \pm 0.029$ & $<0.001$ \\
\hline
\end{tabular}

\section{Survival fitness in the Coast}

The Coast Analog tested the relative survival fitness for exposure to $5 \mathrm{~d}$ in seawater at $14^{\circ} \mathrm{C}$, measured by comparative counts on Days 5 and 10. Measurements shown in Table 5 were calculated with linear population ratios to measure survival fitness, rather than the logarithmic ratios used to measure growth fitness, since the absolute populations often decreased between the beginning and end points of the competition (Fig. 2). None of the Acid, Cycled $\mathrm{pH}$, or $14^{\circ} \mathrm{C}$ Lines showed statistically significant changes in relative seawater survival fitness. However, the $42^{\circ} \mathrm{C}$ Line demonstrated a $12 \%$ gain and, most noteworthy, the Alkaline Line showed an extremely high significant $191 \%$ gain in seawater survival fitness. For an environmental comparison, the natural Host Isolate showed $79 \%$ lower survival fitness and the natural Coast Isolate had $46 \%$ higher survival fitness relative to the common Ancestor/ Control bacterium.

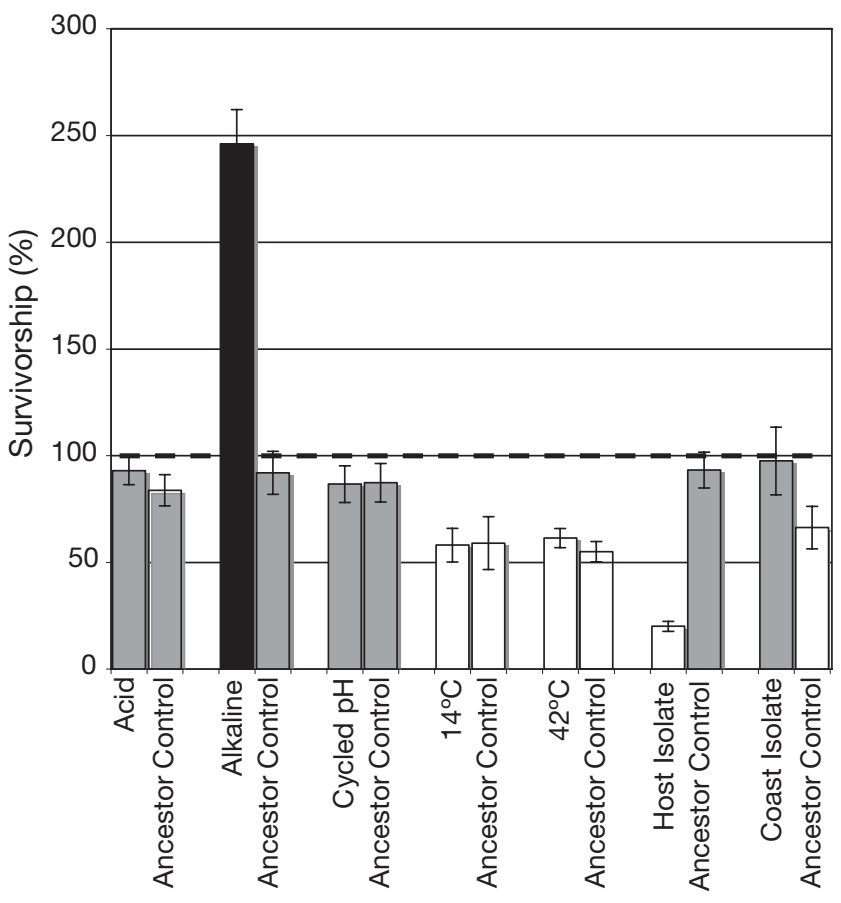

Fig. 2. Absolute survivorship percentage after $5 \mathrm{~d}$ exposure to Host Analog filtered seawater (characterization analysis in Table 3) is shown for each experimental line (Acid, Alkaline, $\mathrm{pH}$ Cycled, $14^{\circ} \mathrm{C}, 42^{\circ} \mathrm{C}$, Host Isolate, and Coast Isolate) paired alongside the survivorship of the matched Ancestor/Control with which it competed in the same flask. Survivorship values significantly higher than $100 \%$ (dashed line) indicate population growth (black bar); those not significantly different from $100 \%$ indicate population persistence (gray bars); and survivorship values significantly less than $100 \%$ indicate population decline (white bars) 
Absolute survival count percentages, measuring actual population persistence and growth, are displayed in Fig. 2, with percentages significantly lower than $100 \%$ (white bar) indicating an inability to persist in seawater, percentages significantly higher than $100 \%$ (black bar) indicating actual growth in seawater, while no significant change (gray bar) represents persistence. Each line's survivorship percentage is paired adjacent to the survivorship percentage of its competing Ancestor/Control Line. Most notable was the $246 \%$ absolute survivorship of the Alkaline Line. This Alkaline Line displayed a $225 \%$ higher population count than the natural Host Isolate Line (calculated here: $1.46-(-) 0.79=2.25$, all relative to a baseline fitness of one, which may be expressed as $225 \%$ ), but this large difference in relative survival fitness was not accompanied by any statistically significant (at $\alpha=0.05$, Tukey-Kramer comparison test) difference between the absolute counts of their paired common ancestral competitors, demonstrating further validity to the dramatic comparison. More importantly this Alkaline Line was the only line that could actually grow during the $5 \mathrm{~d}$ seawater media exposure to the Coast Analog, demonstrating a 146\% increase from its initial count.

\section{Trade-off patterns}

Defined here, a trade-off is a cost or loss of fitness in one environment accompanying a gain of fitness in another environment; a specialist displays trade-offs, while a generalist does not. In the Host Analog, only the Acid and $42^{\circ} \mathrm{C}$ Lines had trade-offs, while in the Coast Analog only the natural Host Isolate Line had trade-offs. This result characterized the Acid, $42^{\circ} \mathrm{C}$, and Host Isolate Lines as specialists. The Alkaline, Cycled $\mathrm{pH}, 14^{\circ} \mathrm{C}$, and Coast Isolate Lines were all Host to Coast generalists.

\section{Pilot replication experiment}

Although each bacterial line was independently tested in 6-fold replication, the large scope of this study prevented replication at the level of measuring multiple evolutionary lineages adapted to each environmental condition (e.g. high temperature). However, as a pilot experiment, 3 independently evolved Acid Lines were tested for analysis of consistency of response. All 3 of the lines (Acid +1 used in this experiment, Acid +2 , and Acid +3 ) were statistically indistinguishable (Tukey-Kramer comparison $\alpha=0.05, \mathrm{n}=6$ samples for each of 3 lines) in their relative fitness in both the Host and the Coast Analog.

\section{DISCUSSION}

The Host to Coast Analog contributed a novel interdisciplinary methodology through integrating experimental evolution with aquatic microbial ecology. Specific evolutionary patterns of growth and survival of Escherichia coli in our ecosystem are of particular concern, considering the importance of this bacterium to environmental health. While abiotic factors were the focus of this ecological Analog model, microbe-tomicrobe interactions played a role in the measurement of relative fitness, since the evolved or natural isolate bacteria competed against a common Ancestor/Control bacterium directly for shared limited nutrients. Tests of evolutionary hypotheses regarding trade-offs, specialists, and generalists, were extended to encompass potential costs of adaptation in more realistically complex multi-stress environments than had ever been examined before. The results of this experiment support the hypotheses that long-term exposure to alkaline $\mathrm{pH}$ can permit the evolution of highly increased survival and growth in seawater, and that long-term cycling between acidic and alkaline environments, such as that increasingly occurring between humans and the oceans with mishandling of sewage, can increase growth fitness in an environment similar to the human gastrointestinal tract.

\section{Growth fitness in the Host}

Since the extreme $\mathrm{pH}$ of the Acid Cycle reduced populations to undetectable levels, populations were enumerated before the Host Analog stomach acidification of Day 10 and again only after the Day 11 simulation of passage through the small intestine. Repopulation during Day 11 from such a small population to densities exceeding millions of cells per ml, reflects the remarkable growth capacities of a bacterium that can colonize a host with as few as 10 cells (Audia et al. 2001) and simulated growth time and passage toward the colon, which is the niche where Escherichia coli are a highly successful competitor (Kaper et al. 2004). Among their main suggestions for future research on E. coli pathogenesis, Kaper et al. (2004) asked what factors allow commensal E. coli strains to colonize and survive so successfully in this niche and also what new strains may be likely to evolve. The Host Analog tested some environmental factors that affect such evolution.

Though counterintuitive, the Acid Line's correlated fitness loss of $62 \%$ in the acidic Host Analog environment agrees with Hughes et al. (2007b), who showed that evolution in constant acidity causes a correlated decrease of fitness in environments of fluctuating acidity. The Host Analog test fluctuated acidity (Fig. 1) to 
reflect the physiology of passage through the stomach and intestines. Evolutionary exposure to fluctuating $\mathrm{pH}$ in the Cycled $\mathrm{pH}$ Line caused a correlated fitness gain of $19 \%$ in the Host Analog, as predicted based on our previous observation that long-term exposure to fluctuating $\mathrm{pH}$ causes increased fitness in cycling $\mathrm{pH}$ (Hughes et al. 2007b). Considering that the Host Analog was a warm environment at $37^{\circ} \mathrm{C}$, it was an unexpected result that the cold $14^{\circ} \mathrm{C}$ Line gained $15 \%$ fitness while the hot $42^{\circ} \mathrm{C}$ Line lost $44 \%$ fitness. Not surprisingly, the natural Host Isolate Escherichia coli strain had the highest performance of relative growth fitness in the Host Analog, which may offer additional validity to the Analog as a simulation of the human host. A concerning pattern emerges, when considering that (1) combinations of cycling $\mathrm{pH}$, constant alkalinity, and cold temperatures (as may occur when sewage is released into the ocean and transported back and forth to mammalian hosts) are factors that can cause E. coli to colonize and survive more successfully in this niche, and (2) the Coast Isolate was very successful in the Host Analog.

Escherichia coli survival during transmission into a human host is dependent upon resistance to $\mathrm{pH}$ damage, involving protein denaturing and depurination of DNA (Richard \& Foster, 2004); 3 underlying mechanisms responsible for $E$. coli $\mathrm{pH}$ resistance have been described (Lin et al. 1995, Hersh et al. 1996 CastanieCornet et al. 1999, De Biase et al. 1999), with one mechanism involving a glutamate decarboxylase GAD system and another mechanism involving an arginine decarboxylase ARG system. In both of these mechanisms, in the presence of either glutamate or arginine, E. coli can reverse the electrical membrane potential, making the inside of the cell positively charged, a strategy used by various acidophiles in extremely low $\mathrm{pH}$ environments (Richard \& Foster 2004). Involvement of the other mechanism, the RpoS system (Small et al. 1994), may be highly suspected, since in seawater there is a 1000-fold greater number of culturable E. coli containing a functional rpoS gene (Munro et al. 1995), and the rpoS819 allele is known to confer a strong fitness advantage at basic $\mathrm{pH}$ while being disadvantageous under acidic conditions (Farrell \& Finkel 2003). Evolution involving rpoS could potentially be partly responsible for the increased seawater survival, although many factors are known to affect the evolution of the RpoS system (for a short review see Ferenci 2008).

\section{Survival fitness in the Coast}

Few studies have measured the response of enteric bacteria under environmental conditions such as those encountered by bacteria in coastal waters (Troussellier et al. 1998). Raw sewage is often discharged into lowtemperature marine environments, raising the question of whether Escherichia coli is able to adapt to and persist in this extreme environment (Winfield \& Groisman 2003). The Coast Analog test begins to answer this question, as results of relative survival fitness values shown in Table 5 revealed increased fitness in seawater relative to the Ancestor/Control as indicated by values significantly higher than 1 .

Although constant acid evolutionary lines lose substantial fitness in otherwise similar alkaline media (Hughes et al. 2007a), this was not the case for the Acid Line tested in the more complex seawater environment of the Coast Analog (Table 5). Cycled pH and cold $14^{\circ} \mathrm{C}$ evolutionary factors were found not to play a significant role in seawater survival fitness. Interestingly, the high temperature evolution of the $42^{\circ} \mathrm{C}$ Line did cause a significant $12 \%$ increase of relative survival fitness in the cold $14^{\circ} \mathrm{C}$ seawater. As predicted to characterize real-world relevance of the Analog system, in an inverse symmetry of performance in the Host Analog test, the Coast Analog test exhibited lower survival fitness for the natural Host Isolate Line and higher survival fitness for the natural Coast Isolate Line, when tested in seawater. Certainly, the most dramatic pattern of correlated relative survival fitness increase occurred in the Alkaline Line's highly significant and substantial gain of $191 \%$ evolved over the common ancestral control, far in excess over even the natural Coast Isolate. While it was predicted that alkalinity was potentially an important factor in seawater survival adaptation, such a large increase suggested it was a critical factor and perhaps even capable of enabling growth in seawater, posing a serious danger and calling into question the application of Escherichia coli as an indicator species.

Since relative survival fitness only measures a ratio between the experimental and ancestral control lines, it does not discern the extent to which lines are actually dying off or growing in a culture. Therefore, an additional measure of absolute survival was employed to ascertain the actual persistence and growth rates over the $5 \mathrm{~d}$ seawater exposure of the Coast Analog (Fig. 2), in which percentages significantly lower than $100 \%$ represent an eventual dead end for a bacterial line with an inability to persist in seawater; persistence near $100 \%$, and percentages significantly higher than $100 \%$ indicate actual growth in seawater. These absolute bacterial population changes are shown in Fig. 2, with each line paired to its Ancestor/Control within a specific competitive match, i.e. competing within the same flask for limited resources. Fig. 2 shows 7 independent survival results for the Ancestor/Control and each competitive match-up would 
presumably dictate different metabolic patterns of nutrient consumption leading to different population counts. For instance, the Ancestor/Control might produce lower populations when in the company of a competitor that would more effectively compete for nutrient resources or vice versa, and such patterns might be apparent in the Host and Coast Isolate Line competitions, respectively. However, excluding more resources from the Ancestor/Control may not translate to higher populations, i.e. the $14^{\circ} \mathrm{C}$ and $42^{\circ} \mathrm{C}$ Lines, if the experimental line is inefficient in yield. Furthermore, consideration of such microbe-to-microbe interactions may pale in comparison to another result, seen in the comparison between the highest and lowest performers in the Coast Analog. Surprisingly, the 225\% population count difference between the Alkaline and natural Host Isolate Lines was not accompanied by any significant difference in the absolute counts of their common ancestral competitor, which may indicate improvement by metabolic efficiency rather than mere exclusion of nutrients from the competitor. However, such interesting considerations were dramatically eclipsed by the singular performance of the absolute survival counts of the Alkaline Line. This Alkaline Line demonstrated its vast superiority over all of the other experimental lines, including the natural Coast Isolate, by being the only line that could actually grow during the $5 \mathrm{~d}$ seawater media exposure in the Coast Analog. Its aggressive performance demonstrated an impressive $146 \%$ climb from its initial count.

\section{Evolutionary conclusions}

Previous studies examining trade-offs with this same bacterial system explored potential costs within the limited conditions of acidity and alkalinity for the $\mathrm{pH}$ lines (Hughes et al. 2007a,b) and at various temperatures for the thermal lines (Bennett \& Lenski 1993, 2007). However, the present study extended the search for correlated trade-offs in the more complex and realistic multi-stress environmental conditions of the Host to Coast Analog. One of the more interesting results was the Acid Line's lack of trade-offs in seawater (Table 5), while this same line exhibited significant costs in other alkaline environments (Hughes et al. 2007a). The $42^{\circ} \mathrm{C}$ Line, which is a thermal generalist without tradeoffs in any previously tested thermal environment (e.g. $42^{\circ} \mathrm{C}=$ REL2051 in Bennett \& Lenski 1993), was shown here to have significant trade-off costs of $44 \%$ in the more complex Host Analog (Table 4). By contrast, this $42^{\circ} \mathrm{C}$ Line had significant $12 \%$ fitness gains in this novel environment of the Coast Analog, which may be considered exaptation (Table 5). The Host Isolate was a Host specialist, exhibiting a fitness gain in the Host and a loss in the Coast Analogs. Since the $14^{\circ} \mathrm{C}$ Line gains in the Host Analog were not accompanied by a trade-off in the Coast Analog, it was a Host to Coast generalist. Likewise, yet reversed, the Alkaline Line was also a Host to Coast generalist, but with gains in the Coast and no trade-offs in the Host Analogs. Such a pattern might suggest the possibility that a more generalist physiology, without substantial costs of specialization, may be produced by natural seawater exposure, and continued laboratory research in this area may substantiate this pattern. Apparently, an evolutionary 'Jack of all trades' can be a master of many, although trade-offs might be revealed in more complex arenas.

\section{Ecological implications}

The evidence that alkaline $\mathrm{pH}$ adaptation also entailed increased survival and unprecedented growth of Escherichia coli in seawater underscored the dangers of environmental exposure to high $\mathrm{pH}$ in wastewater systems prior to release into marine waters. Furthermore, the finding that superior fitness for colonizing a human host was evolved by exposure to cycled fluctuation of $\mathrm{pH}$ and cold $14^{\circ} \mathrm{C}$ temperatures may help inform regulation of wastewater management to prevent evolution of superior strains of pathogenic E. coli possessing generalist physiologies that could facilitate increased growth in coastal seawater and infectiousness in human hosts. Such a fate may be forewarned by the more generalist type of physiology found in the Coast Isolate, and future directions for this research include the controlled experimental evolution of E. coli within the repeated cycling of the Host to Coast Analog and further tests of other natural isolate strains.

Acknowledgements. This research was supported by National Science Foundation grants IBN-9727762 and IBN9905980, and National Aeronautics and Space Administration grant 632731. I thank A. F. Bennett for guidance and support; T. Bradley for discussions of experimental design; S. Jiang for providing natural isolate Escherichia coli samples and seawater filtration; C. Carlson for expertise with seawater testing; S. Grant, W. P. Chu and J. H. Ahn for expertise in seawater sampling and testing; and P. McDonald and E. Hughes for assistance in the culturing laboratory.

\section{LITERATURE CITED}

Ahn JH, Grant SB, Surbeck CQ, Digiacomo PM, Nezlin NP, Jiang SC (2005) Coastal water quality impact of stormwater runoff from an urban watershed in southern California. Environ Sci Technol 39:5940-5953

Audia JP, Webb CC, Foster JW (2001) Breaking through the acid barrier: an orchestrated response to proton stress by 
enteric bacteria. Int J Med Microbiol 291:97-106

Barcina I, Gonzalez JM, Iriberri J, Egea L (1992) Role of protozoa in the regulation of enteric bacteria populations in seawater. Mar Microb Food Webs 5:179-188

Bennett AF (2003) Experimental evolution and the Krogh principle: generating biological novelty for functional and genetic analysis. Physiol Biochem Zool 76:1-11

Bennett AF, Lenski RE (1993) Evolutionary adaptation to temperature. II. Thermal niches of experimental lines of Escherichia coli. Evolution 47:1-12

Bennett AF, Lenski RE (2007) An experimental test of evolutionary trade-offs during temperature adaptation. Proc Natl Acad Sci USA 104:8649-8654

Bennett AF, Lenski RE, Mittler JE (1992) Evolutionary adaptation to temperature. I. Fitness responses of Escherichia coli to changes in its thermal environment. Evolution 46:16-30

Beumer RR, de Vries J, Rombouts FM (1992) Campylobacter jejuni non-culturable coccoid cells. Int J Food Microbiol 15:153-163

Carlson CA, Giovannoni SJ, Hansell DA, Goldberg SJ, Parsons R, Vergin K (2004) Interactions between DOC, microbial processes, and community structure in the mesopelagic zone of the northwestern Sargasso Sea. Limnol Oceanogr 49:1073-1083

Castanie-Cornet MP, Penfound TA, Smith D, Elliott JF, Foster JW (1999) Control of acid resistance in Escherichia coli. J Bacteriol 181:3525-3535

Clarkston WK, Pantano MM, Morley JE, Horowitz M, Littlefield JM, Burton FR (1997) Evidence for the anorexia of aging: gastrointestinal transit and hunger in healthy elderly vs. young adults. Am J Physiol 272:R243-R248

$>$ De Biase D, Tramonti A, Bossa F, Visca P (1999) The response to stationary-phase stress conditions in Escherichia coli: role and regulation of the glutamic acid decarboxylase system. Mol Microbiol 32:1198-1211

Dressman JB, Berardi RR, Dermentzoglou LC, Russell TL and others (1990) Upper gastrointestinal (GI) pH in young, healthy men and women. Pharm Res 7:756-761

Dziuban EJ, Liang JL, Craun GF, Hill V and others (2006) Surveillance for waterborne disease and outbreaks associated with recreational water-United States, 2003-2004. MMWR Surveill Summ 55:1-30

Edberg SC, Allen MJ, Smith DB (1988) National field evaluation of a defined substrate method for the simultaneous enumeration of total coliforms and Escherichia coli from drinking water: comparison with the standard multiple tube fermentation method. Appl Environ Microbiol 54: 1595-1601

Farrell MJ, Finkel SE (2003) The growth advantage in stationary-phase phenotype conferred by $r p o S$ mutations is dependent on the $\mathrm{pH}$ and nutrient environment. J Bacteriol 185:7044-7052

Ferenci $\mathrm{T}$ (2008) The spread of a beneficial mutation in experimental bacterial populations: the influence of the environment and genotype on the fixation of $r p o S$ mutations. Heredity 100:446-452

> Fujioka RS, Hashimoto HH, Siwak EB, Young RH (1981) Effect of sunlight on survival of indicator bacteria in seawater. Appl Environ Microbiol 41:690-696

Gauthier MJ, Munro PM, Flatau GN, Clément RL, Breittmayer VA (1993) Nouvelles perspectives sur l'adaptation des entérobactéries dans le milieu marin. Mar Life 3:1-18

Guyton AC, Hall JE (2000) Textbook of medical physiology, 10th edn. WB Saunders, Philadelphia, PA

Hersh BM, Farooq FT, Barstad DN, Blankenhorn DL, Slonczewski JL (1996) A glutamate-dependent acid resistance gene in Escherichia coli. J Bacteriol 178:3978-3981
Hughes BS, Cullum AJ, Bennett AF (2007a) Evolutionary adaptation to environmental $\mathrm{pH}$ in experimental lineages of Escherichia coli. Evolution 61:1725-1734

> Hughes BS, Cullum AJ, Bennett AF (2007b) An experimental evolutionary study on adaptation to temporally fluctuating pH in Escherichia coli. Physiol Biochem Zool 80:406-421

> Ishii S, Ksoll WB, Hicks RE, Sadowsky MJ (2006) Presence and growth of naturalized Escherichia coli in temperate soils from lake superior watersheds. Appl Environ Microbiol 72:612-621

> Jannasch HW (1968) Competitive elimination of Enterobacteriaceae from seawater. Appl Microbiol 16:1616-1618

> Jimenez L, Muniz I, Toranzos GA, Hazen TC (1989) Survival and activity of Salmonella typhimurium and Escherichia coli in tropical freshwater. J Appl Bacteriol 67:61-69

> Kaper JB, Nataro JP, Mobley HLT (2004) Pathogenic Escherichia coli. Nat Rev Microbiol 2:123-140

> Lenski RE, Rose MR, Simpson SC, Tadler SC (1991) Longterm experimental evolution in Escherichia coli. I. Adaptation and divergence during 2,000 generations. Am Nat 138:1315-1341

> Lin J, Lee IS, Frey J, Slonczewski JL, Foster JW (1995) Comparative analysis of extreme acid survival in Salmonella typhimurium, Shigella flexneri and Escherichia coli. J Bacteriol 177:4097-4104

Lin J, Smith MP, Chapin KC, Baik HS, Bennett GN, Foster JW (1996) Mechanisms of acid resistance in enterohemorrhagic Escherichia coli. Appl Environ Microbiol 62:3094-3100

> Loewen PC, Hengge-Aronis R (1994) The role of the sigma factor $\sigma^{\mathrm{S}}$ (KatF) in bacterial global regulation. Annu Rev Microbiol 48:53-80

- Lopez-Torres AJ, Prieto L, Hazen TC (1988) Comparison of the in situ survival and activity of Klebsiella pneumoniae and Escherichia coli in tropical marine environment. Microb Ecol 15:41-57

> Mendonca AF, Amoroso TL, Knabel SJ (1994) Destruction of gram-negative food-borne pathogens by high $\mathrm{pH}$ involves disruption of the cytoplasmic membrane. Appl Environ Microbiol 60:4009-4014

Montrose MH (2001) Choosing sides in the battle against gastric acid. J Clin Invest 108:1743-1744

Munro PM, Flatau GN, Clement RL, Gauthier MJ (1995) Influence of the RpoS (KatF) sigma factor on maintenance of viability and culturability of Escherichia coli and Salmonella typhimurium in seawater. Appl Environ Microbiol 61:1853-1858

> Naugle AL, Holt KG, Levine P, Eckel R (2006) Sustained decrease in the rate of Escherichia coli O157:H7-positive raw ground beef samples tested by the Food Safety and Inspection Service. J Food Prot 69:480-481

Noble RT, Weisberg SB, Leecaster MK, McGee CD and others (2003) Storm effects on regional beach water quality along the southern California shoreline. J Water Health 1:23-31

> Nugent SG, Kumar D, Rampton DS, Evans DF (2001) Intestinal luminal $\mathrm{pH}$ in inflammatory bowel disease: possible determinants and implications for therapy with aminosalicylates and other drugs. Gut 48:571-577

Richard H, Foster JW (2004) Escherichia coli glutamate- and arginine-dependent acid resistance systems increase internal $\mathrm{pH}$ and reverse transmembrane potential. J Bacteriol 186:6032-6041

Rose MR, Graves JL, Hutchison EW (1990) The use of selection to probe patterns of pleiotropy in fitness characters. In: Gilbert F (ed) Insect life cycles: genetics, evolution and coordination. Springer, New York, p 29-42

Rozen Y, Belkin S (2001) Survival of enteric bacteria in seawater. FEMS Microbiol Rev 25:513-529 
Russell TL, Berardi RR, Barnett JL, Dermentzoglou LC and others (1993) Upper gastrointestinal pH in seventy-nine healthy, elderly, North American men and women. Pharm Res 10:187-196

Sasaki Y, Hada R, Nakajima H, Fukuda S, Munakata A (1997) Improved localizing method of radiopill in measurement of entire gastrointestinal $\mathrm{pH}$ profiles: colonic luminal $\mathrm{pH}$ in normal subjects and patients with Crohn's disease. Am J Gastroenterol 92:114-118

Savageau MA (1983) Escherichia coli habitats, cell types, and molecular mechanisms of gene control. Am Nat 122: 732-744

Small P, Blankenhorn D, Welty D, Zinser E, Slonczewski JL (1994) Acid and base resistance in Escherichia coli and Shigella flexneri: role of rpoS and growth $\mathrm{pH}$. J Bacteriol 176:1729-1737

Editorial responsibility: Hugh Ducklow, Woods Hole, Massachusetts, USA
Solo-Gabriele HM, Wolfert MA, Desmarais TR, Palmer CJ (2000) Presence and growth of naturalized Escherichia coli in temperate soils from lake superior watersheds. Appl Environ Microbiol 66:230-237

Tamplin ML (2005) Inactivation of Escherichia coli O157:H7 in simulated human gastric fluid. Appl Environ Microbiol 71:320-325

Troussellier M, Bonnefont JC, Courties C, Derrien A and others (1998) Responses of enteric bacteria to environmental stresses in seawater. Oceanol Acta 21:965-981

- Vasconcelos GJ, Swartz RG (1976) Survival of bacteria in seawater using a diffusion chamber apparatus in situ. Appl Environ Microbiol 31:913-920

Winfield MD, Groisman EA (2003) Role of nonhost environments in the lifestyles of Salmonella and Escherichia coli. Appl Environ Microbiol 69:3687-3694

Submitted: November 13, 2007; Accepted: September 9, 2008 Proofs received from author(s): November 4, 2008 